\title{
Design and Evaluation of Phyto-Phospholipid Complexes (Phytosomes) of Rutin for Transdermal Application
}

\author{
Malay K Das ${ }^{1}$, Bhupen Kalita ${ }^{2}$ \\ ${ }^{1}$ Department of Pharmaceutical Sciences, Dibrugarh University, Dibrugarh 786004, India. \\ ${ }^{2}$ Girijananda Chowdhury Institute of Pharmaceutical Science, Guwahati, India.
}

\begin{tabular}{l} 
ARTICLE INFO \\
\hline Article history: \\
Received on: $12 / 08 / 2014$ \\
Revised on: 13/09/2014 \\
Accepted on: $29 / 09 / 2014$ \\
Available online: $30 / 10 / 2014$ \\
\hline Key words: \\
Phytosomes, Phospholipid \\
Complex, Rutin, \\
Transdermal.
\end{tabular}

\begin{abstract}
The polyphenolic flavonoid Rutin possesses multiple therapeutic effects out of which the anti-inflammatory potential has been well established in the recent literatures. The oral bioavailability of Rutin is very low necessitating its novel drug delivery approach. Phyto-phospholipid complex (phytosomes) is helpful in enhancing oral bioavailability and transdermal permeation of polyphenols. In the present work, Rutin phytosomes (RN-P) were developed and characterized to establish its feasibility for transdermal application in inflammatory conditions. Phytosomes were prepared in five molar ratios of Rutin $(0.5-1.0)$ to Phosphatidylcholine (1.0 - 0.5). All RN-Ps showed aqueous solubility higher than pure Rutin. Partition coefficient results indicated the lipophilic nature of free Rutin as well as all RN-Ps with most satisfactory value found at $3.11 \pm 0.08$ with F3 formulation. Discrete vesicular structures of RN-Ps observed in TEM study. Results of the FT-IR, DSC and XRD studies confirmed the phyto-phospholipid complex formation. XRD reports revealed the reduction in crystallinity of Rutin when in phytosomes form with F3 found to be the least crystalline. SEM studies confirmed the disappearance of rod shaped crystals of Rutin in phytosome formulations. The ex vivo skin permeation study across excised rat abdominal skin confirmed the higher permeability of RN-Ps (33 $\pm 1.33 \%)$ over pure Rutin (13 $\pm 0.87 \%$ ). The observations made in the present work suggest that phyto-phospholipid complex of Rutin can increase its skin uptake to treat inflammatory conditions in arthritis, rheumatism, athletic aches and may able to deliver the drug for a long duration avoiding the problems associated with oral administration.
\end{abstract}

\section{INTRODUCTION}

Rutin

$\left(3,3^{\prime}, 4^{\prime}, 5,7-\right.$

pentahydroflavone-3rhamnoglucoside) is one of the most common flavonoid constituents of many plants, e.g., Ruta graveolens of Marantaceae family (Kostova et al., 1999; Abdullah et al., 2008) or Sophora japonica (Kim and Yun-Choi, 2008). It possesses antioxidant, anti-inflammatory, antithrombotic, antineoplastic, inhibits ultraviolet radiation-induced cutaneous oxidative stress and inflammation (Saja et al., 1998; Ropke et al., 2002; Casagrande et al., 2007), chemopreventive (Hirose et al., 1999), protective role in liver disease, cataract, and cardiovascular disease (Prabathianana et al., 2010). It is also used to treat capillary fragility and hypertension (Yildzogle-Ari et al., 1991), lowers hepatic as well as blood cholesterol and having antiplatelet activity (Park et al., 2002). Among all beneficial effects,

* Corresponding Author

Malay K Das, Department of Pharmaceutical Sciences, Dibrugarh

University, Dibrugarh 786004 India.Email: mkdps@dibru.ac.in the anti-inflammatory activityof Rutin was being well established in the world literature (Selloum et al., 2003; Obied et al., 2005; Wonhwa et al., 2012; Zeilhofer, 2006; Karki et al., 2013; Bouriche, 2005) and found its application in the treatment of inflammatory conditions associated with excessive leukotriene production, such as rheumatoid arthritis and inflammatory bowel disease (Appleton 2010). However the use of Rutin is relatively limited due to its low water solubility (Pedriali, 2008) and poor bioavailability (Hollman, 1997).

In recent years many novel drug delivery systems were being developed to overcome such drawbacks of Rutin. The 2hydroxypropyl beta cyclodextrine inclusion complex of Rutin was found to possess higher solubility, stability, dissolution rate and oral bioavailability in dog (Miyakeet et al., 2000).

Rabiskova et al., 2012 developed coated chitosan pellets of Rutin for the treatment of inflammatory bowel disease. Rutinphospholipid complexes when tested for physicochemical properties and in vitro antioxidant activity, the results proved better efficiency in the form of complexes as compared to the pure molecules itself 
(Jain et al., 2012). Singh et al., 2012 reported that the Rutinphospholipid complex may be considered as a promising drug delivery system for improving the overall oral absorption and bioavailability of Rutin. Laxmi and Narendra 2012 prepared polymeric nanoparticles of Rutin and reported that Rutin in colloidal carrier enhanced the drug penetration into the skin, and because of its lipoidal nature, the penetrated drug concentrates in the skin and remains localized for a longer period of time, thus enabling drug targeting to the skin. In vitro skin permeation studies on a pig ear model demonstrated that Rutin ethosome formulations were better able to permeate compared to pure Rutin (Dhiman and Singh, 2013). Park et al., 2013 developed liposomein-hydrogel complex system of Rutin to enhance transdermal permeation. The objective of the present study was to formulate phyto-phospholipid complexes (phytosomes) of Rutin and to evaluate the feasibility for its potential transdermal application in inflammatory conditions for sustained therapeutic benefits.

\section{MATERIALS AND METHODS}

\section{Materials}

Rutin was purchased from TCI Chemicals (India) Pvt. Ltd., Chennai. Phosphatidylcholine (PC) (Egg lecithin) was purchased from Sigma Aldrich, Bangaluru.

\section{Preparation of rutin phytosomes (RN-Ps)}

Phytosomes were prepared by refluxing followed by solvent evaporation (Kidd and Head, 2005; Maiti et al., 2007 and Jiang et al., 2001). RN-Ps was prepared in different ratios of Rutin to phosphatidylcholine as shown in Table1. Rutin (RN) was dissolved in methanol in a $200 \mathrm{ml}$ beaker. In a $500 \mathrm{ml}$ round bottomed flux phosphatidylcholine (PC) was dissolved in dichloromethane and Rutin solution was mixed. The mixture was refluxed for 3 hours at $70{ }^{\circ} \mathrm{C}$. After 3 hours the mixture was cooled and then poured to petridish. The dish was kept open overnight at room temperature for evaporation of solvent. Then the product was kept in hot air oven at $60{ }^{\circ} \mathrm{C}$ for 2 hours. The dried product was stored in desiccators for further use.

\section{Physicochemical evaluation of phytosomes Solubility and partitioning}

Solubility studies were performed by taking an excess of the sample in $5 \mathrm{ml}$ of various solvent viz. water, phosphate buffer ( $\mathrm{pH}$ 6.8), acetate buffer ( $\mathrm{pH} 4.5$ ). (Chaudhary and Sharma, 2007). Partition coefficient was determined by shake flask method (Berthod, 2004) using different solvent systems (Table 2).

\section{Drug entrapment}

A weighed quantity of phytosomes equivalent to $10 \mathrm{mg}$ RN was added to $50 \mathrm{ml}$ phosphate buffer pH 6.8 in a $100 \mathrm{ml}$ beaker. The contents were stirred on a magnetic stirrer for 4 hours and then allowed to stand for one hour. Clear liquid was decanted and centrifuged (CF10 Centrifuge, Daihan Scientific Co. Ltd, Korea) at $5000 \mathrm{rpm}$ for 15 minutes. After centrifugation the supernatant was filtered through $0.45 \mu$ whatman filter paper and after suitable dilution absorbance was measured in UV at $257 \mathrm{~nm}$ (UV1800, Shimadju, Japan). The drug entrapment (\%) was calculated using the following formula: Drug entrapment $(\%)=$ Actual amount determined/Theoretical amount present.

\section{Particle size distribution}

The prepared phytosome samples were dispersed in isopropyl alcohol by stirring on a magnetic stirrer for 10 minutes. The dispersion was analyzed in size analyzer (Malvern, Nano series, S90 Zetasizer).

\section{X-Ray diffraction (XRD) study}

XRD was done on pure Rutin and RN-Ps in different ratios of drug and $\mathrm{PC}$ to see the crystallinity in the substance. Sample was scanned in the angular range of $5^{\circ}-80^{\circ}$ in a PHILIPS XPert Pro X-Ray Diffractometer. Dried powder sample was kept in sample holder $(20 \mathrm{~mm} \times 15 \mathrm{~mm} \times 2 \mathrm{~mm})$ which was fitted into the instrument and X-ray was passed through the sample.

\section{Differential scanning calorimetry (DSC)}

DSC studies for pure rutin, phosphatidylcholine (PC), physical mixture of rutin and PC and phytosomes (1:1) were performed on a Perkin Elmer (USA) (Model JADE DSC) differential scanning calorimeter by heating samples over a temperature range of $50-300^{\circ} \mathrm{C}$ in closed metal pans at the rate of $10^{\circ} \mathrm{C}$ per minute under the environment of nitrogen gas.

\section{Fourier Transform Infrared spectroscopy (FT-IR) Study}

FT-IR studies were performed pure rutin, PC, physical mixture of RN and PC and phytosomes (1:1) were performed in an Alpha FT-IR spectrophotometer (Bruker, Germany). A small quantity of sample was placed just below the probe on to which the probe was tightly fixed and scanned in the wave number region 4000-500 $\mathrm{cm}^{-1}$. The obtained IR spectra were interpreted for functional groups at their respective wave number $\left(\mathrm{cm}^{-1}\right)$.

\section{Scanning electron microscopy (SEM)}

Drug and phytosomes samples were coated with gold in a Fine Coat Ion Sputter JFC-1100. Analysis was done on the coated sample by placing a pinch of sample in the JEOL (JSM 6360) Scanning electron microscope and surface morphology was viewed and photographed.

\section{Transmission electron microscopy (TEM)}

Sample was dispersed in water and a drop was placed on a carbon coated copper grid to form a thin film. The film was stained with $2 \%$ uranic acid and allowed to dry by air drying. The stained film was viewed and photographed in a JEOL (JEM 2100) transmission electron microscope.

\section{Ex vivo skin permeation study}

Skin permeation of selected phytosomes formulation (F3) was compared with skin permeation of free $\mathrm{RN}$, as $\mathrm{F} 3$ was found 
Table 1: Composition of various phytosomes formulations.

\begin{tabular}{lccccc}
\hline \multirow{2}{*}{ Ingredients } & \multicolumn{3}{c}{ RN-P (Rutin : Egg lecithin) } \\
\cline { 2 - 6 } & F1(0.5:1.0) & F2 (0.75:1.00) & F3(1:1) & F4 (1.00:0.75) & F5(1.0:0.5) \\
\hline Rutin (gm) & 0.874 & 1.312 & 1.748 & 2.332 & 2.497 \\
Egg lecithin (gm) & 2 & 2 & 2 & 8 \\
Dichloromethane (ml) & 80 & 80 & 80 & 80 & 80 \\
Methanol (ml) & 80 & 80 & 80 & 80 \\
\hline
\end{tabular}

Table 2: Solubility and Partition coefficient data.

\begin{tabular}{|c|c|c|c|c|c|c|}
\hline \multirow[b]{2}{*}{ Sample Name } & \multicolumn{3}{|c|}{ Solubility $(\mathrm{mg} / \mathrm{ml})$} & \multicolumn{3}{|c|}{ Partition coefficient } \\
\hline & Water & $\begin{array}{c}\text { Phosphate } \\
\text { buffer (pH 6.8) }\end{array}$ & $\begin{array}{c}\text { Acetate buffer } \\
\text { (pH 4.5) }\end{array}$ & n-octanol/water & $\begin{array}{c}\text { n-octanol/phosphate } \\
\text { buffer (pH 6.8) }\end{array}$ & $\begin{array}{c}\text { n-octanol/acetate } \\
\text { buffer (pH 4.5) }\end{array}$ \\
\hline Rutin & $0.064 \pm 0.008$ & $0.43 \pm 0.09$ & $0.055 \pm 0.032$ & $7.04 \pm 0.28$ & $6.36 \pm 0.33$ & $8.10 \pm 0.44$ \\
\hline Phytosomes $(0.5: 1)(\mathrm{F} 1)$ & $0.42 \pm 0.02$ & $0.56 \pm 0.16$ & $0.31 \pm 0.13$ & $6.66 \pm 1.52$ & $5.57 \pm 1.29$ & $7.98 \pm 0.32$ \\
\hline Phytosomes $(0.75: 1)(\mathrm{F} 2)$ & $0.522 \pm 0.013$ & $0.78 \pm 0.34$ & $0.407 \pm 0.082$ & $5.64 \pm 1.33$ & $5.07 \pm 0.87$ & $6.82 \pm 0.81$ \\
\hline Phytosomes (1:1) F3 & $0.774 \pm 0.054$ & $2.03 \pm 0.41$ & $0.72 \pm 0.33$ & $4.05 \pm 1.08$ & $3.11 \pm 0.08$ & $4.63 \pm 0.91$ \\
\hline Phytosomes (1:0.75) F4 & $0.484 \pm 0.180$ & $0.62 \pm 0.54$ & $0.35 \pm 0.22$ & $6.29 \pm 0.80$ & $5.27 \pm 1.03$ & $7.04 \pm 0.09$ \\
\hline Phytosomes (1:0.5) F5 & $0.165 \pm 0.220$ & $0.24 \pm 0.08$ & $0.122 \pm 0.340$ & $6.97 \pm 0.67$ & $6.68 \pm 0.58$ & $7.17 \pm 0.22$ \\
\hline
\end{tabular}

*All data represents average of three observations, $\pm \mathrm{SD}(\mathrm{n}=3)$

Table 3: Particle size and drug entrapment.

\begin{tabular}{lcc}
\hline \multicolumn{1}{c}{ Formulation } & Average particle size $(\mathbf{n m}) \pm$ SD $(\mathbf{n}=\mathbf{3})$ & Drug entrapment $(\%) \pm$ SD $(\mathbf{n}=\mathbf{3})$ \\
\hline Phytosome $(0.5: 1)$ (F1) & $684 \pm 2.44$ & $97.38 \pm 1.13$ \\
Phytosome (0.75:1) (F2) & $780 \pm 2.75$ & $95.22 \pm 1.33$ \\
Phytosome (1:1) (F3) & $1202 \pm 3.23$ & $99.62 \pm 0.93$ \\
Phytosome (1:0.75) (F4) & $1562 \pm 3.45$ & $100.54 \pm 1.05$ \\
Phytosome (1:0.5) (F5) & $1628 \pm 3.66$ & $101.08 \pm 1.35$ \\
\hline
\end{tabular}

superior in terms of aqueous solubility, partition coefficient, crystallinity and drug entrapment than other RN-Ps (F1, F2, F4 and F5).

For the study, a modified Franz diffusion cell with a diffusional area of $1.766 \mathrm{~cm}^{2}$ was used. Rat abdominal skin excised after sacrificing the animal was used in the study. Skin hairs were shaved and subcutaneous fats were removed carefully. Skin was mounted in the diffusion cell with the stratum corneum facing the donor compartment and the dermis facing the receptor compartment. To the donor compartment $10 \mathrm{mg}$ Rutin or phytosomes equivalent to $10 \mathrm{mg}$ Rutin was applied on the skin after dispersing in $0.5 \mathrm{ml}$ water.

The receptor compartment was filled with $32 \mathrm{ml}$ phosphate buffer (pH 6.8) and maintained at $37 \pm 0.5^{\circ} \mathrm{C}$ under continuous stirring with a magnetic bar. From the receptor compartment $2 \mathrm{ml}$ samples were withdrawn at predetermined time intervals up to 24 hours. Same volume of receptor compartment fluid was replaced after each sampling. Experiment was carried out in triplicate following the same procedure. Samples were analyzed in UV-Visible Spectrophotometer at $257 \mathrm{~nm}$. The cumulative amount permeated at each time interval was calculated and a plot of cumulative amount permeated $(\mathrm{Q}, \%)$ versus time $(\mathrm{t}$, h) was constructed.

The skin after 24 hours study was taken out of the diffusion assembly and was cut into small pieces and extracted with methanol by homogenizing in a tissue homogenizer. Aliquots of the extract were analyzed in the UV-Visible Spectrophotometer at $257 \mathrm{~nm}$ after suitable dilution with phosphate buffer ( $\mathrm{pH} 6.8$ ).

\section{RESULTS AND DISCUSSION}

\section{Preparation of phytosomes}

We prepared RN-Ps in five different ratios of drug to phosphatidylcholine. All formulations appeared pale yellow in color and were in lumps, i.e. not free flowing. Formulations with higher phospholipid content $(0.5: 1$ and $0.75: 1)$ found to be more viscous and sticky lumps. In phyto-phospholipid complex preparation obtaining a clear solution of drug and PC in the reaction solvent is a prerequisite. Dichloromethane was chosen for dissolving PC but rutin is insoluble in this mixture. Rutin is soluble in methanol. Dichloromethane and methanol are miscible with each other at any volume. Rutin and PC were dissolved separately in methanol and dichloromethane respectively and the two solutions were mixed and then refluxed (Table 1).

\section{Solubility and partitioning}

Rutin as reported in many literatures (Miyake et al., 2000; Mauludin et al., 2009) found to be highly hydrophobic in nature with water solubility $0.0639 \pm 0.008 \mathrm{mg} / \mathrm{ml}$. While its aqueous solubility in basic $\mathrm{pH}$ is higher $(0.426 \pm 0.091 \mathrm{mg} / \mathrm{ml})$ than in acidic $\mathrm{pH}(0.0551 \pm 0.032 \mathrm{mg} / \mathrm{ml})$. Rutin phytosomes were found to be better soluble than pure Rutin with the order of solubility in phosphate buffer $\mathrm{pH} 6.8>$ water $>$ acetate buffer $\mathrm{pH}$ 4.5 (Table2). The amount soluble in $\mathrm{mg} / \mathrm{ml}$ significantly varied as the ratio of Rutin to phosphatidylcholine varied. Highest solubility was observed for F3 where the molar ratio of Rutin to Phosphatidylcholine is 1:1. Results show that F3 solubility in 
phosphate buffer $\mathrm{pH} 7.4$ is much higher $(2.025 \pm 0.41 \mathrm{mg} / \mathrm{ml})$ than in water $(0.774 \pm 0.054 \mathrm{mg} / \mathrm{ml})$ and acetate buffer $\mathrm{pH} 4.5(0.716 \pm$ $0.33 \mathrm{mg} / \mathrm{ml}$ ). Compared to $\mathrm{F} 3$, in case of $\mathrm{F} 1$ and $\mathrm{F} 2$ aqueous solubility in basic, neutral and acidic medium were found very less (table-2). The reason may be the higher quantity of PC that remained unbound where $\mathrm{RN}$ : $\mathrm{PC}$ ratios were $0.5: 1(\mathrm{~F} 1)$ and 0.75:1(F2). The unbound PC might form extra layers surrounding the RN-P vesicles. On the other hand less solubility also observed in case of F4 and F5 in comparison to F1 (Table 2).

The reason may be attributed to higher quantity of Rutin that remained unbound where RN: PC ratios were 1:0.5 (F4) and 1:0.75 (F5). Partition coefficient can be considered as an important factor for predicting skin permeability from an aqueous environment to the lipophilic stratum corneum (Cal, 2006). For transdermal absorption the permeant should possess (octanolwater) partition coefficient in the range -1.0 to 4.0 (Chandrasekhar and Shobharani, 2008; Panchagnula, 1997) The results of the partition coefficient study are presented in Table 2. Partition coefficient values of pure RN were $7.04 \pm 0.28$ (ocanol/water), $6.36 \pm 0.33$ (octanol/Phosphte buffer $\mathrm{pH}$ 6.8) and $8.10 \pm 0.44$ (octanol/acetate buffer $\mathrm{pH}$ 4.5). The results indicate lipophilic nature of RN. Partition coefficient value when exceed 3 may retard drug absorption via skin due to difficulty in permeating the hydrophilic epidermis/dermis beneath the SC (Schneider et al., 2009; Hung et al., 2010). Keeping this fact in mind the most satisfactory partition coefficient value for RN-P was exhibited by F3 $(3.11 \pm 0.08)$ taking phosphate buffer $\mathrm{pH} 6.8$ as the aqueous medium. Aqueous solubility of drug as well as n-octanol/water partition coefficient are important factors in designing formulations for transdermal application and deciding the fate of permeant for transdermal absorption. However, skin permeation of drug not solely dependent on lipophilicity, but there may be multiple factors and the way the viable dermis respond to a particular permeant.

\section{Drug entrapment}

All phytosomes formulations contain near to $100 \%$ of drug (Table 3). The results indicate uniform binding of drug and phosphatidylcholine. In formulation F1 and F2 the relatively lower drug content $(97.38 \%$ and $95.22 \%$ ) may be due to the presence of unbound phosphatidylcholine where Rutin was in 0.5 and 0.75 fraction. In formulation F3, F4, and F5 molar content of RN was higher than phosphatidylcholine and that is why drug and PC obtained sufficient opportunity to interact with each other as PC provide more than one site for drug binding resulting in higher drug content of $99.62 \%$ to $101.08 \%$.

\section{Particle size}

Average particle size varied between $684 \mathrm{~nm}$ to $1628 \mathrm{~nm}$ (Table 3). The results indicate that as the molar fraction of RN increased in phytosomes from 0.5 (F1) to 2 (F5), the particle size gradually increased. The reason may be attributed to the availability of number of $\mathrm{RN}$ molecule as compared to phospholipid molecule in contact during complex formation.

\section{X-Ray diffraction study}

XRD of RN shows intense crystalline peaks (Figure 1), indicating higher crystallinity of the drug. Such peaks are relatively less intense in phytosome formulations. Among the phytosome formulations, F3 exhibited least number of crystalline peaks, and it was interpreted that F3 (phytosome 1:1) would be more amorphous than phytosomes prepared in other ratios of $\mathrm{RN}$ : PC, i.e. 0.5:1, 0.75:1, 1:0.75 and 1:0.5

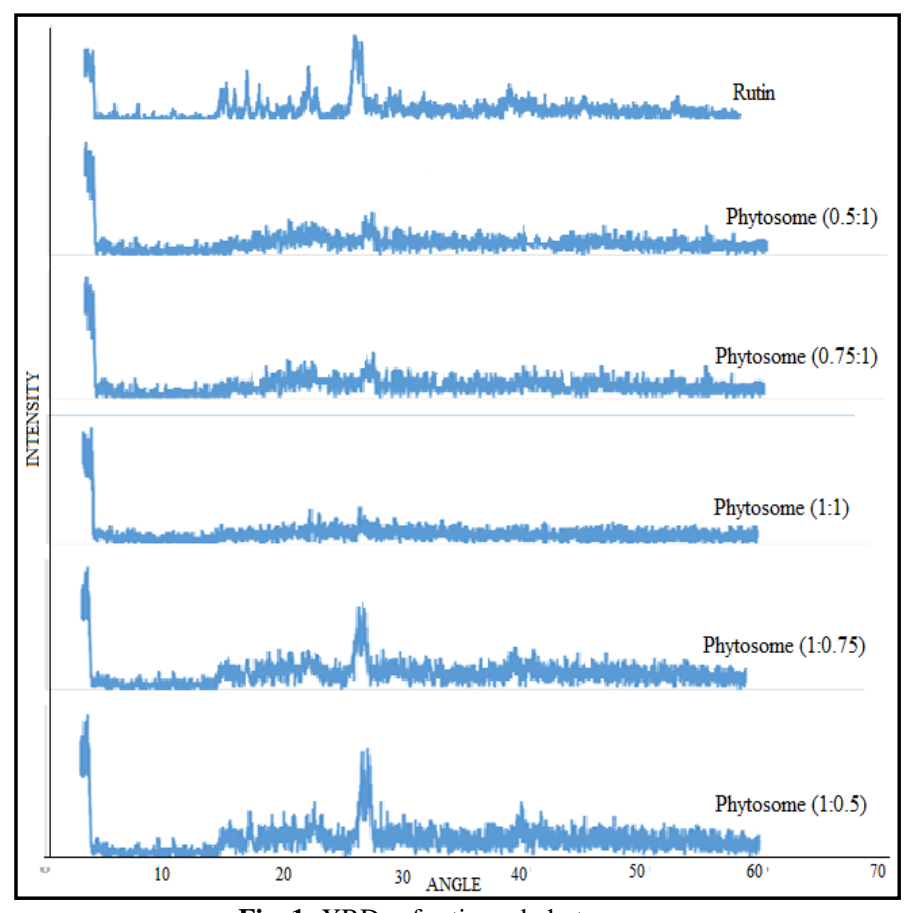

Fig. 1: XRDs of rutin and phytosomes.

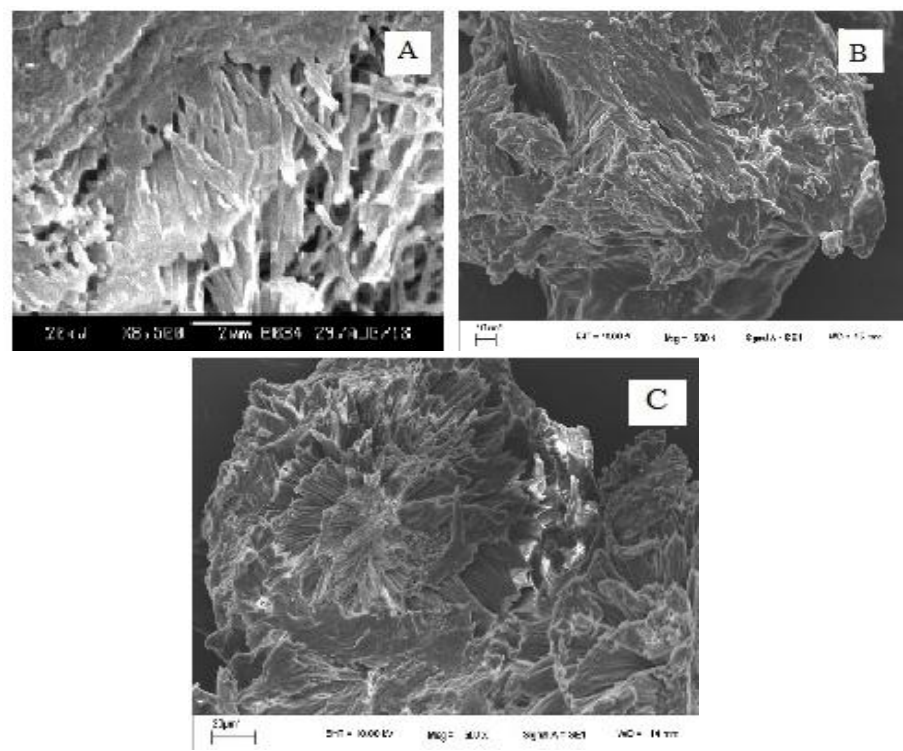

Fig. 2: SEM photographs of (A) rutin, (B) phytosomes (1:1) (F3), (C) phytosomes $(1: 0.5)(\mathrm{F} 4)$

\section{Scanning electron microscopy (SEM)}

SEM photographs give important insight into the solid state properties and surface morphology of drug and drug 
complexes. The highly crystalline state of Rutin was visualized in the SEM photograph as numerous rod shaped crystals. Such crystalline structures were found in some complexes (F4, F5) but absent in the others (F1, F2, and F3). From these results it was assumed that phytosomes complex formation was incomplete in F4 (1:0.5) and F5 (1:0.75) and still drug exist in original rod shaped crystals. Whereas in formulation F1 (0.5:1), F2 (0.75:1) and F3 (1:1) drug completely converted to phytosomes where RN was physically enwrapped by PC imparting amorphous nature to the complexes due to which the rod shaped crystals disappeared.

\section{FT-IR study}

Rutin showed IR absorption (Figure 3) at wave number $\left(\mathrm{cm}^{-1}\right)$ 3743-3228 (O-H stretching), 2936, 2900 (- $\mathrm{CH}_{2}$ stretching), 1759 (-C=O group), 1652, $1596(-\mathrm{C}=\mathrm{C}), 1499$ (aromatic ring), 1359, 1289 (C-O-C). The IR spectra of physical mixture of RN and PC, phytosomes are superimposable with that of pure RN. This eliminates the possibility of any incompatibility of these combinations. Further, it can also be read that RN-PC complexes (phytosomes) involve only weak physical bonding. These results are in good agreement with those of Freag et al., 2013 who reported that some weak physical interactions took place between diosmin $(-\mathrm{OH})$ and the phospholipid phosphate group during complex formation.

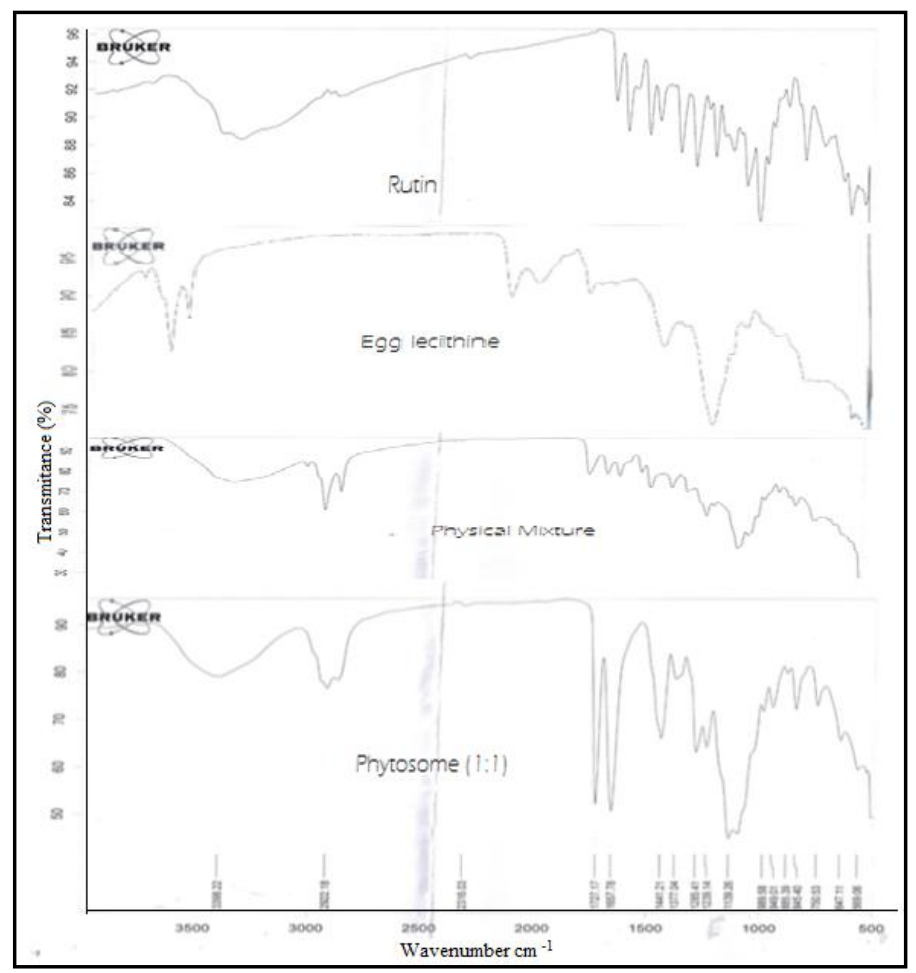

Fig. 3: FT-IR Spectra of rutin, phosphatidylcholine, physical mixture of RN \& PC and phytosome formulation.

\section{Differential scanning calorimetry (DSC)}

DSC thermogram of PC shows endothermic peak at $150.4^{\circ} \mathrm{C}, 172.7^{\circ} \mathrm{C}$ and $180.8^{\circ} \mathrm{C}$. RN shows broad endothermic peak at $175.6^{\circ} \mathrm{C}$. The physical mixture of $\mathrm{PC}$ and $\mathrm{RN}$ shows endothermic peak at $149.57^{\circ} \mathrm{C}$ and $174.89^{\circ} \mathrm{C}$, respectively, which are almost $1^{\circ} \mathrm{C}$ lower than the single compounds. The peaks for $\mathrm{PC}$ at $172.7^{\circ} \mathrm{C}$ and $180.8^{\circ} \mathrm{C}$ were not detectable in the physical mixture. The DSC thermogram of phytosomes gives two endothermic peaks at $145.8^{\circ} \mathrm{C}$ and $171.31^{\circ} \mathrm{C}$, which were at still lower temperature than the physical mixture; also the peaks for the single compounds PC and RN disappeared. For the complexes the phase transition temperature was lower than the phase transition temperature of PC. The thermogram suggests some kind of interaction between PC and RN. Such interaction according to Xu et al., 2009 results from combination of hydrogen bonds or van der Waals forces, but the interaction does not lead to the formation of new compound. After the combination of RN and the PC through weak bonding, the carbon-hydrogen chain in phosphatidylcholine could turn freely and enwrap the phospholipids molecule polarity parts to which drug is bonded, which made the sequence decrease between phospholipids aliphatic hydrocarbon chains, made the endothermic peak of phospholipids ( at $180.8^{\circ} \mathrm{C}$ ) disappear and depressed the phase transition temperature (Figure 4).

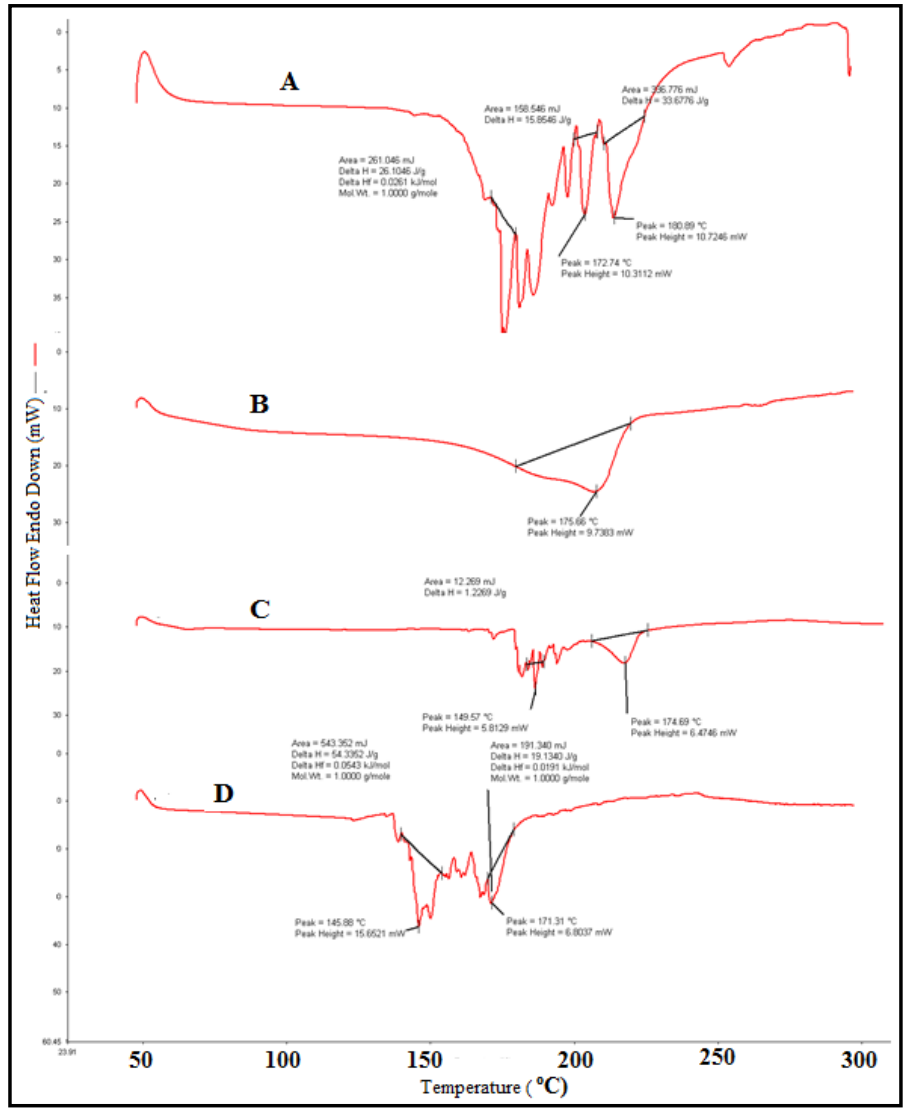

Fig. 4: DSC thermogram of PC (A), RN (B), Physical mixture of RN and PC (C), Formulation F3 (D)

\section{Transmission electron microscopy (TEM)}

TEM study reveals the formation of discrete vesicular structure which appeared as imperfect spheres (Figure 5). When dispersed in water by slightly shaking, phytosomes arranged themselves in order as a response to surface tension. TEM 
photographsof RN-P depicts the established theory that phytosomes results from the effective physical enwrapment of the polyphenol by one or more PC molecules (Kidd, 2009).
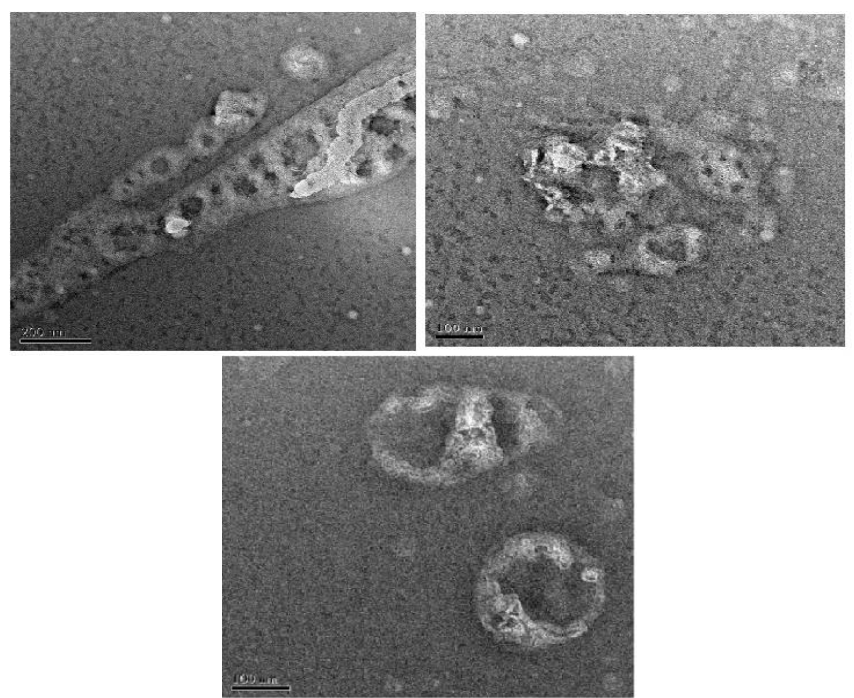

Fig. 5: TEM photographs of phytosomes (1:1) (F3).

\section{Ex vivo skin permeation study}

Skin uptake of RN-P was found to be greater than RN. At the end of 24 hours $13 \pm 0.87 \%$ of RN was released whereas a higher amount of RN $(33 \pm 1.33 \%)$ was found in case of RN-P in the receptor fluid (Figure 6).

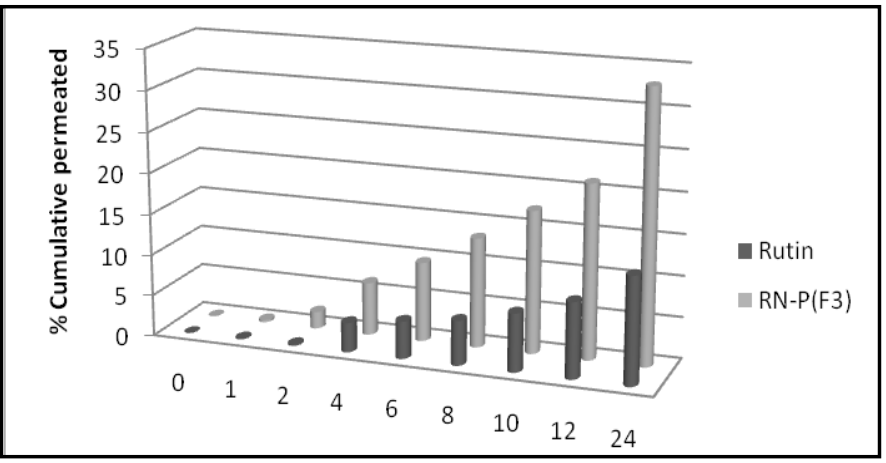

Time (hr)

Fig. 6: Comparison of skin permeation profile of RN and RN-P. All data points represents average of three observations $(n=3)$.

The results show higher permeability of RN-Ps, where phosphatidylcholine played a major role in bringing the RN molecules via the lipophilic stratum corneum to epidermal dermal site and passing the viable dermis which is hydrophilic in nature. $\mathrm{RN}$ as well as RN-P was lipophilic as discussed in partition coefficient results; do not find easy passage through the viable dermis, which may be the reason of lower cumulative (\%) permeation after 24 hours. This increases the possibility of accumulation of $\mathrm{RN}$ either in free form or as complex at the epidermal dermal site beneath the stratum corneum, as it was reported in earlier works that phyto-phospholipid complexes enhance the passage through the outer lipophilic horney layers (Semalty et al., 2008; Chen et al., 2012). The skin extract obtained from the skin used for permeation study of free $\mathrm{RN}$ revealed that it contains $17 \pm 1.06 \% \mathrm{RN}$. Whereas the skin extract obtained from permeation study using F3 showed $44 \pm 1.52 \%$ RN content. The results suggest that the $\mathrm{RN}$ phytosomes are better able to penetrate the highly impermeable stratum corneum than free RN. Retention of this higher quantity of RN will be available for slow passage through the viable dermis and prolonged anti-inflammatory effect at superficial as well as deep skin and adjacent muscular tissues and bone interlocks for getting relief in arthritis, rheumatism, athletic aches etc.

\section{CONCLUSIONS}

Phytosomes first developed and patented by the Italian firm Indena, after which many of the polyphenolic bioflavonoids were being made into phytosomes such as silybin, green tea polyphenols, grape seed proanthrocyanidin, curcumin, etc. Rutin has got serious oral bioavailability problem though it possess potent anti-inflamatory effect. Observations made in the present work suggest that the rutin phytosomes can increase the skin uptake of rutin to treat inflammation leading to pain and swelling either superficial or deep skin. Rutin phytosomes may able to deliver rutin for a long duration as supported by the results of 24 hours permeation study, for relief in arthritis, rheumatism, athletic aches. Further investigation is needed to develop transdermal patch incorporating the optimized phytosome suitable for application on the skin surface.

\section{REFERENCES}

Harborne JB, Grayer. Flavonoids and insects. In: Harborne JB, Editor. The flavonoids: advances in research since 1986. London: Chapman \& Hall; 1993. p. 559-618.

Kostova I, Ivanova A, Mikhova B, Klaiber I. Alkaloids and coumarins from Rutagraveolens. Mon. Chem 1999; 130: 703-707.

Abdullah Y, Schneider B, Petersen M. 2008. Occurrence of rosmarinic acid, chlorogenic acid and rutin in Marantaceae species. Phytochem.Lett 2008; 1: 199-203.

Kim JM, Yun-Choi HS. Anti-platelet effects of flavonoids and flavonoid glycosides from Sophora japonica. Arch. Pharm. Res 2008; 31: 886-890.

Saja A, Tomaino A, Trombetta D, Giacchi M, De Pasquale A, Bonina F. Influence of different penetration enhancers on in vitro skin permeation and in vivo photoprotective effect of flavonoids. Int. J. Pharm 1998; 175: 85-94.

Ropke CD, Kaneko TM, Radrigues RM, Silva VV, Barros S, Sawada TCH, et al. Evaluation of percutaneous absorption of 4nerolidylcathechol from four topical formulations. Int. J. Pharm 2002; 249: 109-116.

Casagrande R, Georgetti SR, Verri WA, Borin MF, Lopez RFV, Fonseca MJV. In vitro evaluation of quercetin cutaneous absorption from topical formulations and its functional stability by antioxidant activity. Int. J. Pharm2007; 328: 183-190.

Hirose M, Takahashi S, Ogawa K, Futakuchi M, Shirai T. Phenolics: blocking agents for heterocyclic amine-induced carcinogenesis. Food Chem. Toxicol 1999; 37: 985-992.

Parabathina RK, Swamy PL, V. V. S. N. Harikrishna G, Rao S, Rao KS. Vitamin-E, Morin, Rutin, Quercetin prevents tissue biochemical changes induced by Doxorubicin in oxidative stress conditions: Effect on heart, liver and kidney homogenates. J. Chem. Pharm. Res 2010; 2(4): 826-834 
Yildzogle-Ari N, Altan V, Altinkurt O, Ozturk Y. Pharmacological effects of rutin. In Phytother. Res 1991; 5: 19-23.

Park SY, Bok SH, Jeon SM, Park YB, Soon-Jae Lee SJ, TaeSook Jeong TS, Choi MS. Effect of rutin and tannic acid supplements on cholesterol metabolism in rats. Nutr Res 2002; 22: 283-295.

Selloum L, Bouriche H, Tigrine C, Boudoukha C. Antiinflammatory effect of rutin on rat paw oedema, and on neutrophils chemotaxis and degranulation. Exp Toxicol Pathol 2003; 54(4): 313-8.

Obied HK, Allen MS, Bedgood DR, Prenzler PD, Robards K, Stockmann R. Bioactivity and analysis of biophenols recovered from olive mill waste. J. Agric. Food Chem2005; 53: 823-837.

Wonhwa L, Sae-Kwang K, Jong-Sup B. Barrier protective effects of rutin in LPS-induced inflammation in vitro and in vivo. Food and Chemical Toxicology 2012; 50: 3048 3055.http://dx.doi.org/10.1016/j.fct.2012.06.013

Zeilhofer $\mathrm{H}$, Brune $\mathrm{K}$. Analgesic strategies beyond the inhibition of cyclooxygenases. Trends Paharmacol Sci 2006; 27(9): 467474.

Karki R, Park CH, Kim DW. Extract of buckwheat sprouts scavenges oxidation and inhibits pro-inflammatory mediators in lipopolysaccharide-stimulated macrophages (RAW264.7). J Integr Med 2013; 11(4): 246-252.

Bouriche H, Miles FA, Selloum L, Calder PC. Effect of Cleome arabica leaf extract, rutin and quercetin on soybean lipoxygenase activity and on generation of inflammatory eicosanoids by human neutrophils. Prostaglandins Leukot Essent Fatty Acids 2005; 72: 195-201.

Appleton J. Evaluating the Bioavailability of Isoquercetin. Natural Medicine Journal 2010; 2(1): 1-6.

Pedriali CA, Fernandes AU, Bernusso LC, Polakiewicz B. The synthesis of a water-soluble derivative of rutin as an antiradical agent. Quím. Nova 2008; 31(8): 2147-2151. http://dx.doi.org/10.1590/S010040422008000800039

Hollman PCH, van Trijp JMP, Mengelers MJB, de Vries JHM, Katan MB. Bioavailability of the dietary antioxidant flavonol quercetin in man. Cancer Lett 1997; 14: 139-140.

Miyake K, Arima H, Hirayama F, Yamamoto M, Horikawa T, Sumiyoshi H, Noda S, Uekama K. Improvement of solubility and oral bioavailability of rutin by complexation with 2-hydroxypropyl -betacyclodextrin. Pharm Dev Technol 2000; 5 (3): 399-407.

Rabiskova M, Bautzova T, Gajdziok J, Dvorackova K, Lamprecht A, Pellequer Y, Spilkova J. Coated chitosan pellets containing rutin intended for the treatment of inflammatory bowel disease: in vitro characteristics and in vivo evaluation. Int J Pharm 2012; 422 (1-2): 151159. doi: 10.1016/j.ijpharm.2011.10.045. Epub 2011 Nov 3

Jain S, Dhanotiya C, Malviya N. Physicochemical characterization and determination of free radical scavenging activity of rutin-phospholipid complex. Int J Pharm Sci Res 2012; 3(3): 909-913.

Singh D, SM Rawat M, Semalty A, Semalty M. RutinPhospholipid Complex: An Innovative Technique in Novel Drug Delivery System- NDDS. Current Drug Delivery 2012; 9(3): 305-314. http://dx.doi.org/10.2174/156720112800389070

Laxmi B, Narendra G. Development of biocompatible nanoparticles for sustained topical delivery of Rutin. Int J Pharm Biol Arch 2012; 3(2): 326-332.

Dhiman A, Singh D. Development, characterization \& in vitro skin permeation of rutin ethosomes as a novel vesicular carrier. Int J Biomed Res 2013; 4(10): 559-566.

Park SN,Lee MH, Kim SJ, Ryeong Yu E. Preparation of quercetin and rutin-loaded ceramide liposomes and drug-releasing effect in liposome-in-hydrogel complex system. Biochem Biophys Res Commun 2013; 435(3): 361-366. http://dx.doi.org/10.1016/j.bbrc.2013.04.093

Kidd PM, Head K. A review of the bioavailability and clinical efficacy of milk thistle Phytosome: a silybin-phosphatidylcholine complex. Alternative Med Rev 2005; 10(3): 193-203.
Maiti K, Mukherjee K, Gantait A, Saha BP, Mukherjee PK. Curcumin-phospholipid complex: preparation, therapeutic evaluation and pharmacokinetic study in rats. Int J Pharm 2007; 330: 155-163. http://dx.doi.org/10.1016/j.ijparm.2006.09.025PMid17112692

Jiang YN, Yu ZP, Yan ZM, Chen JM. Studies on preparation of herbaepimediiflavanoidphytosomes and their pharmaceutics. Zhongguo Zhong Yao Za Zhi 2001; 26(2): 105-108.

Chaudhari P, Sharma P, Barhate N, Kulkarni P, Mistry C. Solubility enhancement of hydrophobic drugs using synergistically interacting cyclodextrins and cosolvent. Current Sci 2007; 92(11): 15861591

Berthod A, Carda-Broch S. Determination of liquid-liquid partition coefficients by separation methods. J Chromatography A 2004 1037: 3-14.

Mauludin R, Muller RH, Keck CM. Kinetic solubility and dissolution velocity of rutin nanocrystals. European J Pharm Sci 2009 36(4-5): 502-510.

DOI

$10.1016 /$ j.ejps.2008.12.002

$\mathrm{Cal} \mathrm{K}$. How does the type of vehicle influence the in vitro skin absorption and elimination kinetics of terpenes? Arch. Dermatol. Res 2006; 297: 311-315.

Chandrashekar NS, Shobha Rani RH. Physicochemical and pharmacokinetic parameters in drug selection and loading for transdermal drug delivery. Indian J Pharm Sci 2008; 70(1):94-96.

Panchagnula R. Transdermal delivery of drugs. Indian J Pharmacol 1997; 29: 140-56.

Schneider M, Stracke F, Hansen S, Schaefer UF. Nanoparticles and their interactions with the dermal barrier. Dermato-Endocrinol 2009; 1: $197-206$.

Hung CF, Lin YK, Zhang LW, Chang CH, Fang JY. Topical delivery of silymarin constituents via the skin route. Acta Pharmacol. Sin 2010; 31: 118-126.

Freag MS, Elnaggar YSR, Abdallah OY. Lyophilized phytosomal nanocarriers as platforms for enhanced diosmin delivery: optimization and ex vivo permeation. Int J Nanomed 2013; 8: 2385-2397. http://dx.doi.org/10.2147/IJN.S45231

Xu K, Liu B, Ma Y, Du J, Li G, Gao H, et al. Physicochemical properties and antioxidant activities of luteolin-phospholipid complex. Molecules 2009; 14: 3486-3493. Doi:10.3390/molecules14093486.

Kidd PM. Bioavailability and activity of phytosome complexes from botanical polyphenols: The Silymarin, Curcumin, Green Tea, and Grape Seed Extracts. Alternative Med Rev 2009; 14(3): 226-246.

Semalty A, Semalty M, Rawat MS. Development and characterization of novel herbal drug delivery system (Phytosomes) of xanthones isolated from Swertia alternifolia for improving bioavailability. In: Dobhal R, Kotlia BS, editors. Science and Technology in Uttarakhand. New Delhi: Macmilan; 2008. pp. 247-53.

Chen Y, Wu Q, Zhang Z, Yuan L, Liu X, Zhou L. Preparation of curcumin-loaded liposomes and evaluation of their skin permeation and pharmacodynamics. Molecules 2012; 17: 5972-5987. Doi:10.3390/molecules17055972.

How to cite this article:

Malay K Das, Bhupen Kalita. Design and Evaluation of PhytoPhospholipid Complexes (Phytosomes) of Rutin for Transdermal Application. J App Pharm Sci, 2014; 4 (10): 051-057. 